\title{
Caracterização física, química e microbiológica de presunto cru desossado adicionado de lactulose
}

\author{
Physical, chemical and microbiological characterization of deboned dry-cured ham \\ with added lactulose
}

\author{
Ítalo Abreu Lima', Hewerton Barbosa Gomes², Alcinéia de Lemos Souza Ramos², Roberta Hilsdorf Piccoli², \\ Eduardo Mendes Ramos ${ }^{2 *}$
}

'Instituto Federal de Educação, Ciência e Tecnologia da Bahia (IFBA), Campus Barreiras, Barreiras/BA - Brasil

2Universidade Federal de Lavras (UFLA), Departamento de Ciência dos Alimentos, Lavras/MG - Brasil

\section{*Corresponding Author}

Eduardo Mendes Ramos, Universidade Federal de Lavras (UFLA), Departamento de Ciência dos Alimentos, Caixa Postal: 3037, CEP: 37200-000, Lavras/MG - Brasil, e-mail: emramos@dca.ufla.br

Cite as: Physical, chemical and microbiological characterization of deboned dry-cured ham with added lactulose. Braz. J. Food Technol., v. 20, e2016028, 2017.

Received: Mar. 08, 2016; Accepted: Dec. 19, 2016

\section{Resumo}

Objetivou-se o desenvolvimento e caracterização tecnológica e microbiológica de presunto cru desossado contendo lactulose como prebiótico. Os presuntos foram elaborados utilizando-se a transglutaminase como agente ligante e glucona-delta-lactona como acidulante, sendo avaliadas uma formulação controle e outra com adição de $2 \%$ de lactulose (LAC). Ambos os produtos obtidos atenderam aos padrões físico-químicos e microbiológicos determinados na legislação brasileira para presuntos crus. A perda de massa na etapa de secagem foi maior $(P<0,05)$ nos produtos adicionados de lactulose do que no controle. Não foram encontradas diferenças significativas $(P>0,05)$ entre os tratamentos para os parâmetros avaliados durante o processamento, com os valores de umidade, atividade de água (aw) e nitrito residual reduzindo-se $(P<0,05)$ e os valores de acidez, bactérias ácido-lática e índice de TBARS aumentando $(P<0,05)$ com a maturação. Os produtos elaborados apresentaram pH $(5,55 \pm 0,37)$ e aw $(0,90 \pm 0,01)$ condizentes com produtos curados dessecados, não havendo $(P>0,05)$ diferenças entre os tratamentos para a composição centesimal e a cor final dos produtos. O teor de lactulose no produto $L A C$ foi de $1,44 \% \pm 0,37 \%$, o que indica a viabilidade da utilização desse prebiótico na elaboração de presuntos crus desossados com vistas à alegação de produto com propriedade funcional.

Palavras-chave: Prebiótico; Produto curado dessecado; Maturação; Cor.

\section{Summary}

The objective was to develop and characterize technologically and microbiologically a boneless dry-cured ham containing lactulose as a prebiotic. The dry-cured hams were processed using transglutaminase as the binder and glucono-delta-lactone as the acidifying agent, evaluating one control formulation and another with the addition of $2 \%$ lactulose (LAC). Both products obtained complied with the physical, chemical and microbiological standards set by the Brazilian legislation for dry-cured hams. The mass losses during the drying stage were higher $(P<0.05)$ for the products containing added lactulose than for the control. No significant differences were found $(P>0.05)$ between treatments for the evaluated parameters during processing, with the moisture content, water activity (aw) and residual nitrite reducing $(P<0.05)$, and the acidity, lactic acid bacteria and TBARS values increasing $(P<0.05)$ during the ripening stage. The finished products showed $\mathrm{pH}(5.55 \pm 0.37)$ and aw $(0.90 \pm 0.01)$ values consistent with dried cured products, with no differences $(P>0.05)$ between treatments for the proximate composition and colour of the products. The lactulose content of the LAC product was $1.44 \pm 0.37 \%$, indicating the feasibility of using this prebiotic in the preparation of boneless dry-cured hams in order to obtain products with a functional property claim.

Keywords: Prebiotic; Dry-cured product; Ripening; Colour. 


\section{Introdução}

No Brasil, houve um aumento no consumo de produtos cárneos processados nos últimos anos, e, por esse motivo, a indústria tem investido na aplicação de tecnologias que propiciem o desenvolvimento de produtos que atendam às expectativas do consumidor, principalmente nos quesitos qualidade e saúde. Nesse sentido, uma atenção especial tem sido dada aos alimentos funcionais, produto definido pela Agência Nacional de Vigilância Sanitária (ANVISA) como

[...] alimento ou ingrediente que, além das funções nutricionais básicas, quando consumido como parte da dieta usual, produz efeitos metabólicos e, ou, fisiológicos e, ou, efeitos benéficos à saúde, devendo ser seguro para o consumo sem supervisão médica (BRASIL, 1999).

A legislação brasileira define "propriedade funcional" e "propriedade de saúde" e estabelece as diretrizes para sua utilização. A alegação "alimento funcional" pode ser obtida através do uso de um ingrediente funcional na elaboração do produto, como, por exemplo, um prebiótico: componentes alimentares (ingredientes) utilizados para fornecer às bactérias presentes no intestino fontes de carbono e de energia seletivas, que Ihes proporcionem vantagem competitiva sobre outras bactérias do ecossistema, modificando, assim, seletivamente a composição da microbiota (FAO, 2008).

Um prebiótico que tem ganhado destaque na área de alimentos como ingrediente funcional é a lactulose, isômero da lactose. A lactulose é um dissacarídeo constituído de galactose e frutose (4-O- $\beta$-D-galactopiranosil-D-frutose), que não é metabolizado nem absorvido no intestino delgado, mantendo-se disponível para as bactérias no intestino grosso, onde é metabolizado preferencialmente pelas bifidobactérias e lactobacilos, o que the confere status de composto funcional (TAMURA et al., 1993; PANESAR; KUMARI, 2011). Entre os efeitos desejáveis da lactulose para a saúde humana citam-se: promoção do equilíbrio da microbiota intestinal; redução de amônia no sangue; aumento da absorção de minerais, como cálcio e magnésio; redução do risco de carcinogênese; e redução nos níveis de triglicerídeos sanguíneos (SCHOLZ-AHRENS et al., 2001). A alegação de propriedade funcional da lactulose foi aprovada pela Comissão Tecnocientífica de Assessoramento em Alimentos Funcionais e Novos Alimentos da Anvisa (BRASIL, 2008), podendo assim ser usada como ingrediente na elaboração de produtos com apelo funcional. Apesar de sua potencialidade, há poucas pesquisas sobre o uso da lactulose como ingrediente funcional em produtos cárneos.

Uma alternativa para o uso da lactulose é a elaboração de produtos cárneos desossados, curados e dessecados, tipo presunto cru. Presuntos crus são considerados nobres, sendo muito apreciados por suas características sensoriais de aroma e sabor, embora sua comercialização no Brasil vise público com poder aquisitivo mais alto. Tradicionalmente, presuntos crus têm sido comercializados como peças inteiras, mas, nos últimos anos, clara expansão do mercado para o produto desossado tem ocorrido, vendido inteiro ou fatiado (ROMERO DE ÁVILA et al., 2014). A fabricação de presuntos crus desossados oferece vantagens durante a produção, uma vez que reduz o tempo de salga e maturação, tendo sido utilizados com sucesso agentes ligantes como a enzima transglutaminase (COSTA et al., 2007; BERGAMIN FILHO et al., 2010; PALHARES et al., 2011) e fibrinas do plasma sanguíneo (ROMERO DE ÁVILA et al., 2014). Além de serem mais adequados para as operações de cortar e fatiar, a elaboração de presuntos crus desossados também facilita a incorporação de ingredientes funcionais.

Dessa forma, objetivou-se com este trabalho elaborar e caracterizar, por meio de análises físico-químicas e microbiológicas, presuntos crus desossados adicionados de prebiótico (lactulose).

\section{Material e métodos}

Para elaboração dos presuntos, pernis suínos com selo de inspeção federal foram obtidos no comércio local, levados ao Laboratório de Tecnologia de Carnes e Derivados (LabCarnes) do Departamento de Ciência de Alimentos da Universidade Federal de Lavras - UFLA e desossados manualmente em pedaços cárneos sem tamanho determinado. Foram realizados dois tratamentos: controle (CONT) e adição de $2 \%$ de lactulose (LACT), obtida a partir de xarope de lactulose Farlac ( 667 mg lactulose/mL; Farmasa, SP).

O processamento dos produtos baseou-se no descrito por Bergamin Filho et al. (2010). Como mistura de salga, foram usados 3\% de cloreto de sódio, 150 ppm de nitrito de sódio, 300 ppm de nitrato de sódio, 0,25\% de glicose, $0,25 \%$ de sacarose e $0,3 \%$ de glucona-delta-lactona (GDL), além da lactulose no tratamento LACT. A GDL foi usada para acelerar o processo de maturação (PALHARES et al., 2011). A mistura de salga foi distribuída manualmente sobre os cortes e esses foram transferidos para uma câmara frigorífica $\left(4^{\circ} \mathrm{C}\right)$. Após cura inicial de 24 horas, as peças foram transferidas para uma misturadeira (modelo MJ35; Jamar Industries Ltd., São Paulo, Brasil), adicionadas de $0,5 \%$ de solução Tranglutaminase Activa ${ }^{\circledR}$ GS 25\% (Ajinomoto Co., Inc.) e misturadas por 15 minutos. Em seguida, as peças foram separadas em porções de $500 \mathrm{~g}$ e acomodadas em formas plásticas, sendo prensadas e mantidas sob refrigeração $\left(4^{\circ} \mathrm{C}\right)$ por 48 horas para salga/cura e equalização. Após desenformados, os produtos foram mantidos novamente sob refrigeração $\left(4^{\circ} \mathrm{C}\right.$; $65 \%$ de umidade relativa) por quatro dias (pós-salga), para finalizar a equalização do sal nos produtos e acelerar o início da secagem. Os produtos foram, então, cobertos com uma pasta feita de toucinho e $2 \%$ de cloreto de sódio, para evitar a secagem excessiva da parte exterior do produto 
(PALHARES et al., 2011), e mantidos novamente em câmara climatizada, agora com temperatura de $16,8^{\circ} \mathrm{C} \pm 0,1^{\circ} \mathrm{C}$ e umidade relativa de $76,3 \% \pm 2,9 \%$ para secagem e maturação. Durante todo o processo, as peças foram pesadas periodicamente, por 30 dias, depois foram lavadas com água potável $\left( \pm 40^{\circ} \mathrm{C}\right)$ e solução de ácido lático $1,5 \%$, embaladas a vácuo e novamente mantidas sob temperatura de $16{ }^{\circ} \mathrm{C}$ por 24 horas, para equalização final da peça, quando o produto foi considerado acabado. A perda de massa durante a elaboração foi calculada e expressa em percentual.

Durante a fase de elaboração dos presuntos foram realizadas amostragens nos tempos dia 0 (zero - salga), 7 dias (final da pós-salga), 21 dias (durante a secagem) e 30 dias (produto acabado), sendo conduzidas as seguintes análises: $\mathrm{pH}$ e acidez titulável (\% ác. lático), segundo Matos et al. (2007); umidade, por secagem em estufa a $105^{\circ} \mathrm{C}$ (HORWITZ, 2002); atividade de água, em aparelho Aqualab CX2 (Decagon Devices Inc.); teor de nitrito residual (ppm), pelo método oficial n. 973.31 da Horwitz (2002); substâncias reativas ao ácido tiobarbitúrico (TBARS; mg malonaldeído/kg), segundo Raharjo et al. (1992), sendo a concentração de malonaldeído (MDA) determinada a partir de curva analítica com 1,1,3,3-tetraetoxipropano (TEP) como padrão; e contagem de bactérias do ácido láctico, coliformes totais e coliformes termotolerantes a $45^{\circ} \mathrm{C}$, segundo metodologias descritas por Silva et al. (2001).

O teor de lactulose foi avaliado na massa (dia 0) e no produto acabado (dia 30) pela adaptação da metodologia descrita por Zhang et al. (2010). Cerca de $10 \mathrm{~g}$ do produto foram homogeneizados (modelo Turratec TE 102; TECNAL, Piracicaba, SP, Brasil) em $50 \mathrm{~mL}$ de água destilada, sendo o homogenato filtrado. Um aliquota de $1,0 \mathrm{~mL}$ do filtrado foi misturada a 2,8 $\mathrm{mL}$ de ácido sulfúrico 75\% em um tubo de ensaio e esse foi mantido em banho-maria $\left(46^{\circ} \mathrm{C}\right)$ por 5 minutos. Após esse período, foram adicionados $0,2 \mathrm{~mL}$ de reagente de cloridrato de cisteína-triptofano (1,25 g de cisteína e $40 \mathrm{mg}$ de triptofano dissolvidos em $50 \mathrm{~mL}$ de HCL 0,01 M) e o tubo foi mantido em banho-maria $\left(46^{\circ} \mathrm{C}\right)$ por mais 70 minutos. $\mathrm{O}$ tubo de ensaio foi resfriado em água corrente por cerca de 5 minutos e a solução, lida em espectrofotômetro a $518 \mathrm{~nm}$ contra o branco. A concentração de lactulose no produto foi determinada a partir de curva analítica com solução padrão de lactulose.

Os produtos também foram avaliados quanto a composição centesimal (proteína, extrato etéreo e cinzas), segundo as metodologias oficiais da Horwitz (2002), e quanto a cor instrumental, segundo Ramos e Gomide (2007). Os índices de cor no sistema CIELAB ( $L^{*}, a^{*}$ e $b^{*}$ ) foram obtidos com um colorímetro CM700 (Konica Minolta Sensing Inc., Japão), utilizando o iluminante D65, observador $10^{\circ}$, luz especular excluída e considerando-se o valor médio de cinco leituras realizadas em diferentes pontos da superfície interna. A saturação $\left(C^{*}\right)$ e o ângulo de tonalidade ( $h^{*}$, em graus) foram calculados pelas seguintes fórmulas: $C^{\star}=\left(a^{\star 2}+b^{\star 2}\right)^{0,5}$ e $h^{\star}=\tan ^{-1}\left(b^{*} / a^{*}\right)$.

O experimento foi conduzido em um delineamento inteiramente casualizado (DIC), no esquema de parcela subdividida, com 2 tratamentos (CONT e LAC) na parcela, 4 tempos de elaboração (dia 0, 7 dias, 21 dias e 30 dias) na subparcela e 3 repetições. Foram produzidas quatro peças de meio quilo para cada tratamento por repetição. A lactulose foi avaliada considerando-se dois tempos: dia 0 e 30 dias. Os dados foram interpretados por meio da análise de variância (ANOVA), considerando-se um nível de 5\% de significância, e, quando necessário, as médias foram comparadas pelo teste de Duncan. Para avaliação da perda de massa dos produtos durante o processamento, os dados foram analisados por regressão, sendo avaliada a interação tempo de processo $x$ tratamento pelo teste F.

\section{Resultados e discussão}

A perda de massa dos produtos foi avaliada em duas etapas: na pós-salga $\left(4^{\circ} \mathrm{C}\right.$; UR 65\%); e na secagem $\left(16^{\circ} \mathrm{C}\right.$; UR $\left.\sim 76 \%\right)$. Não houve efeito $(P>0,05)$ do tratamento na perda de massa durante a etapa de pós-salga, com os produtos atingindo uma perda média de $16,7 \% \pm 2,1 \%$ no final do sétimo dia de processamento. Durante a etapa de secagem, no entanto, houve efeito $(P<0,05)$ do tempo de maturação e dos tratamentos isolados, sendo a perda de massa média ligeiramente maior $(25,19 \% \pm 7,19 \%)$ nos produtos contendo lactulose do que nos produtos controle $(23,94 \% \pm 7,15 \%)$. Essa maior perda foi decorrente da inclusão do xarope de lactulose nas amostras LACT, o que implicou na adição de massa (água e açúcares) facilmente removida do produto durante o processo.

A perda de massa seguiu $(P<0,05)$ um comportamento linear (Figura 1), sendo que para a finalização dos produtos,

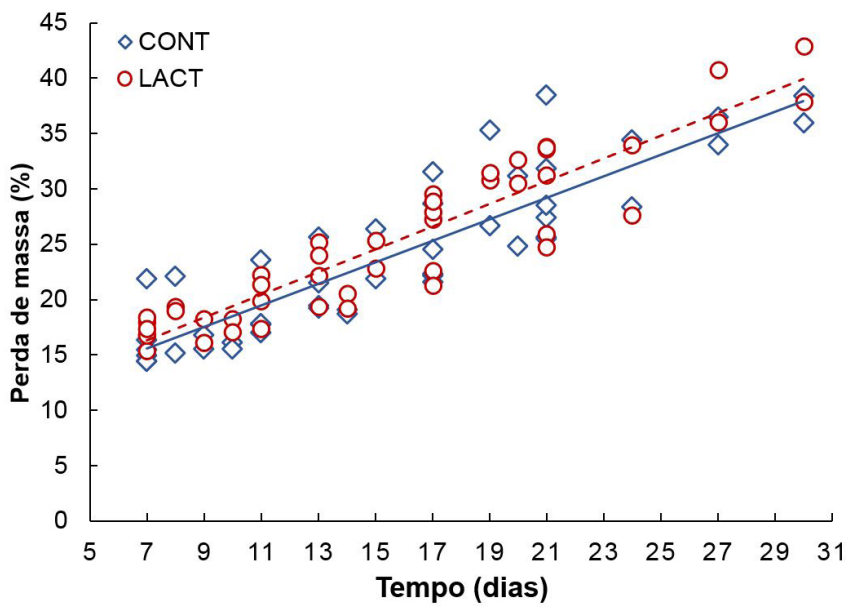

Figura 1. Perda de massa (Perda $=1,0012^{*}$ tempo $+8,9137$; $\mathrm{R}^{2}=0,81$ ) dos presuntos crus desossados, controle (CONT) e adicionado de $2 \%$ de lactulose (LACT) durante a etapa de secagem. 
considerando-se uma perda média de 40\%, foi necessário um tempo médio de 30 dias $/ 0,5 \mathrm{~kg}$. Palhares et al. (2011) observaram serem necessários cerca de 60 dias/kg para que a perda de massa de um produto curado dessecado de ovino, adicionado de GDL, fosse de 40\%. Menores tempos de secagem, no entanto, foram relatados por Bergamin Filho et al. (2010), que avaliando o processamento de presuntos crus desossados e dessecados em peças de $5 \mathrm{~kg}$ constataram perda de $40 \%$ de massa no produto em 115 dias, contados a partir da etapa de secagem, o que condiz com um tempo de processo de $\sim 23$ dias $/ \mathrm{kg}$.

Vários fatores interferem na taxa de secagem de produtos curados, desde o pH da matéria-prima cárnea às condições de secagem (temperatura, velocidade do ar e umidade relativa da câmara), peso e formato da peça/produto (TOLDRA, 2002). De forma geral, a menor taxa de secagem observada neste experimento pode estar relacionada à elevada perda de massa durante a etapa pós-salga, ocasionada pela baixa umidade relativa (65\%) na câmara. Nessa etapa, um defeito similar ao "anel de desidratação" observado em salames (FREY, 1983; TERRA et al., 2004) ocorreu: a retirada de água do produto de forma muito rápida (Figura 2), dessecando rapidamente a sua superfície externa e dificultando, assim, a saída de água do mesmo durante a etapa de secagem.

Apesar da diferença de perda de massa entre os tratamentos na etapa de secagem, a umidade e a atividade de água dos produtos foram afetadas $(P<0,05)$ apenas pelo tempo de processamento, uma vez que a perda de massa durante o processo foi decorrente da perda de água por evaporação e gotejamento, associada à redução gradativa nos valores de umidade e atividade de água observada nos produtos (Figura 2). Nos produtos acabados, o valor médio de atividade de água foi de 0,90 \pm 0,01, abaixo do máximo $(0,92)$ exigido pela legislação brasileira para presunto cru (BRASIL, 2000) e dos 0,91 relatados por Fernández-Salguero (1995), para se considerar um produto estável, sem necessidade de armazenamento refrigerado.

Em presuntos crus é esperado que os valores de $\mathrm{pH}$ aumentem ligeiramente (de 5,8 para próximo de 6,0) após a salga e nos períodos iniciais de maturação, mas esses permanecem basicamente inalterados durante o resto do período de secagem (TOLDRA, 2002). Esse aumento inicial é atribuído à exposição de grupos básicos de aminoácidos, que ocorre devido às reações proteolíticas (BERGAMIN FILHO et al., 2010), oriundas da ação microbiana e, ou, da atividade de enzimas endógenas. No presente estudo, no entanto, os valores de $\mathrm{pH}$ não se alteraram $(P>0,05)$, embora a temperatura de secagem tenha sido mantida na faixa considerada ótima $\left(15^{\circ} \mathrm{C}\right.$ a $\left.20^{\circ} \mathrm{C}\right)$ para a ação proteolítica em produtos cárneos (PUOLANNE; PETÄJÄ-KANNINEN, 2014). O curto período de maturação, que pode ter induzido uma pequena proteólise, e o crescimento $(P<0,05)$ de bactérias ácido-láticas durante 0 processamento, induzindo um aumento $(P<0,05)$ da acidez dos produtos (Figura 3), podem justificar a manutenção dos valores de $\mathrm{pH}$ durante todo o processamento. Além disso, também não houve efeito significativo $(P>0,05)$ dos tratamentos, com os produtos apresentando um $\mathrm{pH}$ médio de 5,55 $\pm 0,37$. Este $\mathrm{pH}$ baixo, provavelmente induzido pela adição de GDL, reforça que os produtos elaborados são estáveis à temperatura ambiente, uma vez que apresentaram $\mathrm{pH} \leq 5,7$ e atividade de água $\leq 0,90$ (FERNÁNDEZ-SALGUERO, 1995).

De forma geral, a acidez nos produtos acabados $(2,16 \pm 0,23 \%$ de ác. lático) foi maior do que o valor médio de 1,52\% observado por Palhares et al. (2011) para perna de cordeiro curada, desossada e maturada com adição de GDL. Já a contagem de bactérias láticas nos produtos
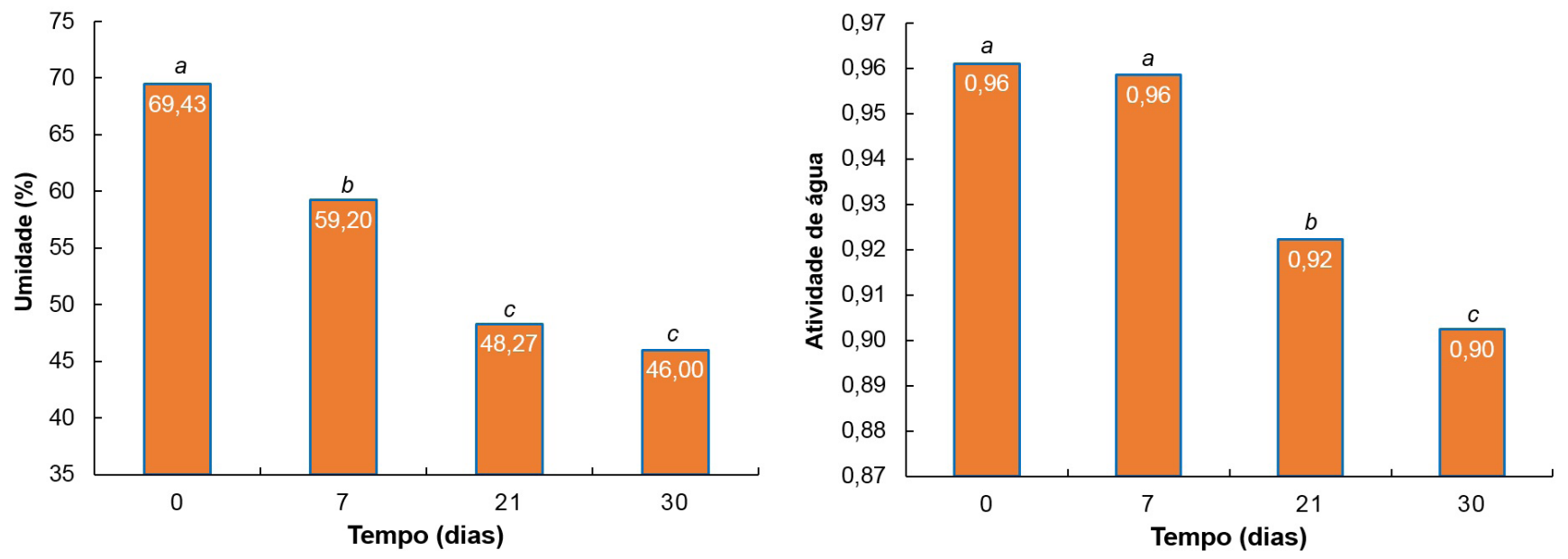

Figura 2. Valores médios ( \pm erro padrão) de umidade e atividade de água durante a elaboração de presuntos crus desossados: salga (dia 0); final da pós-salga (7 dias); durante a secagem (21 dias); e no produto acabado (30 dias). Médias seguidas pela mesma letra não diferem $(P>0,05)$ entre si pelo teste de Duncan. 
esteve próxima dos valores $(6,15 \log$ UFC/g) relatados por (BERGAMIN FILHO et al., 2010) em presuntos crus desossados. Além disso, a contagem de coliformes totais e, especialmente, de coliformes termotolerantes nos presuntos crus $(<10 \mathrm{NMP} / \mathrm{g}$ ) esteve abaixo do limite de $10^{3} \mathrm{NMP} / \mathrm{g}$ coliformes a $45^{\circ} \mathrm{C}$, especificado pela resolução RDC n. 12, de 2 de janeiro de 2001, da Anvisa (BRASIL, 2001) para produtos cárneos maturados.

Para a concentração residual de nitrito de sódio e para o grau de oxidação lipídica (índice de TBARS), verificou-se efeito $(P<0,05)$ apenas do tempo de processamento. A redução observada na concentração do nitrito adicionado (Figura 4) deveu-se à sua conversão a óxido nítrico (NO) e subsequente reação com os pigmentos heme e outros compostos presentes na massa cárnea (HONIKEL, 2008). Nas fases seguintes à pós-salga, os valores de nitrito residual não se alteraram, concentração menor do que os $18,46 \mathrm{ppm}$ foi observada por Bergamin Filho et al. (2010) em presuntos crus desossados.

A quantidade de nitrito residual máxima permitida pela legislação brasileira (BRASIL, 2006) para produtos cárneos é de 150 ppm. As interações do nitrito com a porção heme dos pigmentos da massa cárnea evita que ele se oxide, o que the confere uma característica antioxidante (PEGG; SHAHIDI, 2000). Essas reações são ainda mais importantes em produtos dessecados, onde a rancidez oxidativa se desenvolve naturalmente, induzida pela ação pró-oxidante do sal adicionado e pela quantidade de ácidos graxos livres liberados em consequência da ação lipolítica da microbiota ou de sistemas enzimáticos endógenos (TOLDRA, 2002; PUOLANNE; PETÄJÄ-KANNINEN, 2014). Essa oxidação foi constatada pelo aumento nos valores de índice de TBARS durante a etapa de secagem (Figura 4), atingindo um valor final médio de
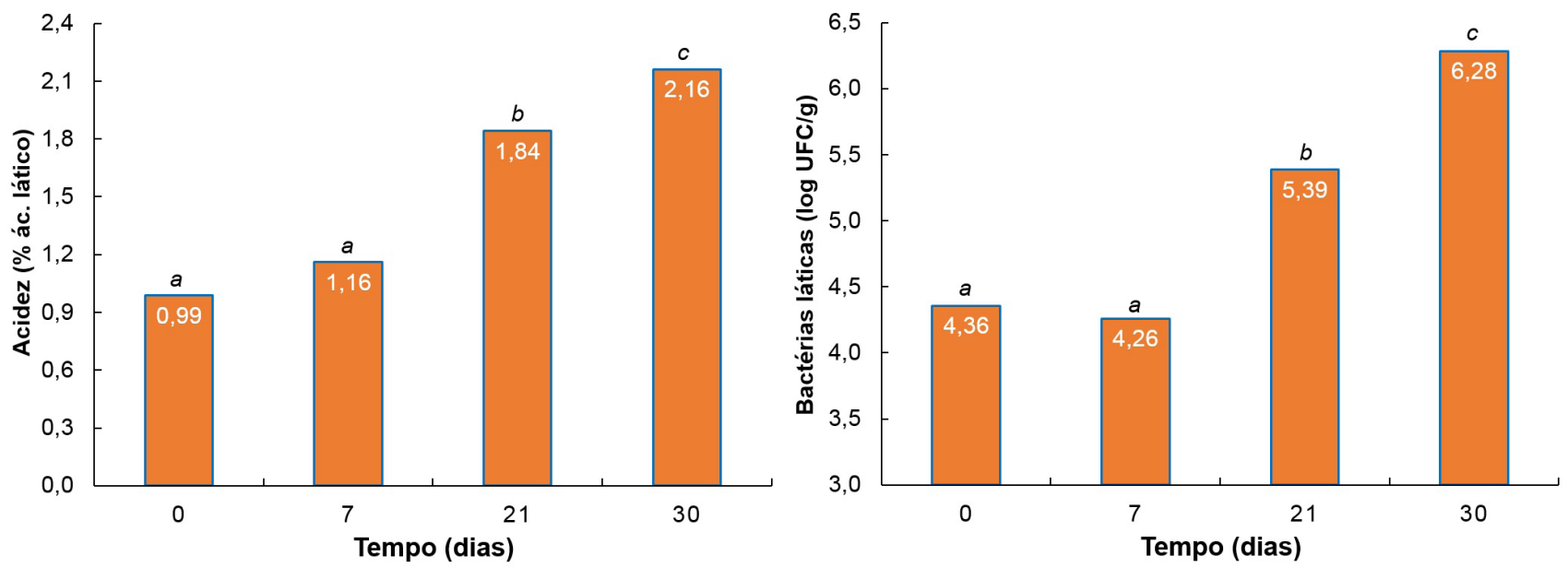

Figura 3. Valores médios ( \pm erro padrão) de acidez e contagem de bactérias láticas durante a elaboração de presuntos crus desossados: salga (dia 0); final da pós-salga (7 dias); durante a secagem (21 dias); e no produto acabado (30 dias). Médias seguidas pela mesma letra não diferem $(P>0,05)$ entre si pelo teste de Duncan.
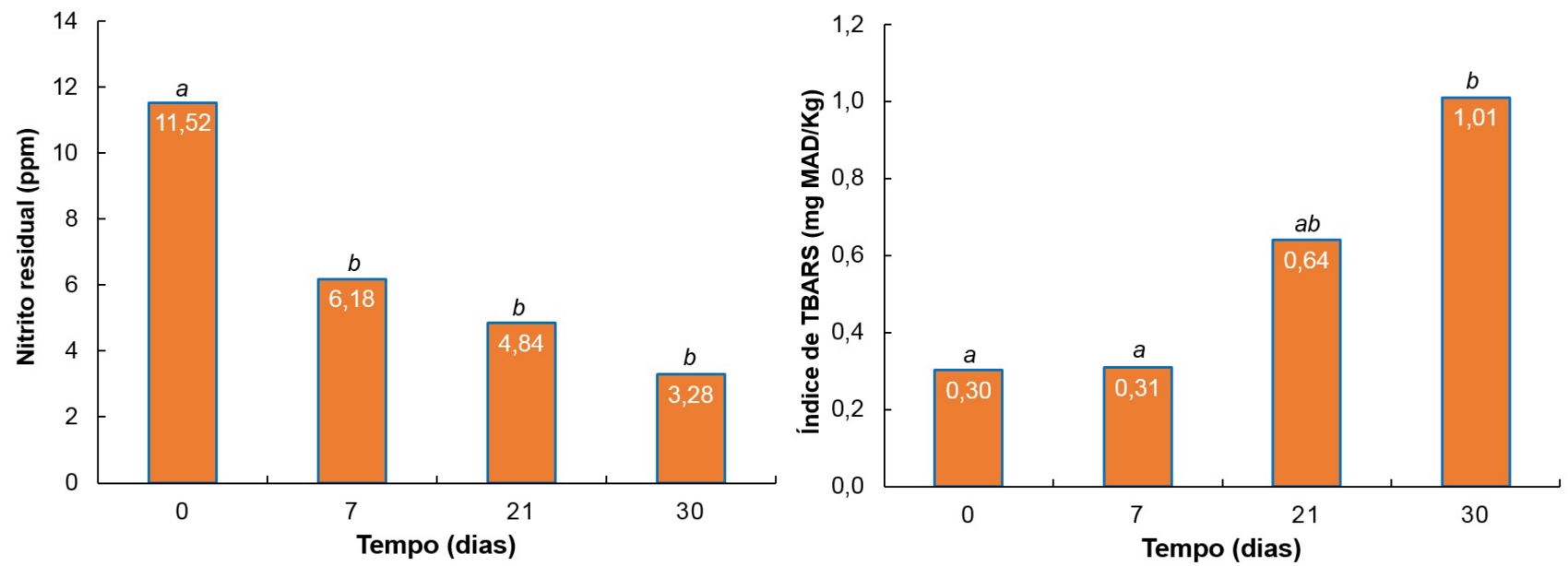

Figura 4. Valores médios ( \pm erro padrão) de nitrito residual e índice de TBARS durante a elaboração de presuntos crus desossados: salga (dia 0); final da pós-salga (7 dias); durante a secagem (21 dias); e no produto acabado (30 dias). Médias seguidas pela mesma letra não diferem $(P>0,05)$ entre si pelo teste de Duncan. 
Caracterização física, química e microbiológica de presunto cru desossado adicionado de lactulose

Lima, I. A. et al.

1,01 mg MAD $\pm 0,68$ mg MAD/kg. Bermúdez et al. (2014) também verificaram um aumento nos valores de TBARS durante a elaboração de presunto cru, que atingiram valor médio ao final do processamento de 1,48 mg MDA/kg. Valores similares (1,41 mg MA/kg) também foram reportados por Coutron-Gambotti e Gandemer (1999) em presuntos crus ao final de 24 meses de processamento. Segundo Toldra (2002), além da acidez e da proteólise, uma certa quantidade de oxidação é desejada para se obter sabor e aroma característicos de produtos curados dessecados.

A composição centesimal e a cor instrumental dos presuntos crus estão descritas na Tabela 1. De forma geral, a adição de lactulose no produto não influenciou suas características físicas e químicas, que se mantiveram dentro do que preconiza a legislação brasileira (BRASIL, 2000) quanto ao teor de gordura (máximo de 20\%) e de proteínas (mínimo de 27\%) para presuntos crus.

A cor é a principal característica da aparência de produtos curados (RUIZ et al., 2002), podendo influenciar na escolha do consumidor quando o presunto é comercializado fatiado. Costa et al. (2008) avaliaram as diferenças nos índices de cor de presuntos crus desossados $(L=39,95 ; C=11,71$; e hue $=10,97) \mathrm{com}$ produtos comerciais importados $(L=31,60 ; C=14,09$; e hue $=10,97)$ e produzidos no Brasil $(L=33,39 ; C=14,03$; e hue $=10,86)$. Porém esses autores utilizaram o iluminante A na leitura das amostras e expressaram os índices no sistema de cor Hunter Lab, o que impossibilitou a comparação direta (RAMOS; GOMIDE, 2007) com os resultados deste experimento. A título de comparação, convertendo os índices médios do presente experimento para o sistema Hunter Lab e iluminante $A$, os presuntos elaborados foram bem mais claros $(L=53,34)$, com tom de vermelho ligeiramente mais alaranjado ( hue $=14,17$ ) e com intensidade de cor $(C=14,45)$ semelhante aos produtos comercializados no Brasil. Essa diferença pode estar associada a muitos fatores, desde a matéria-prima utilizada (espécie e idade do animal, condições de criação, tipo de músculos utilizados etc.) até as características do processamento (ingredientes utilizados, tempo de salga e maturação etc.). A imagem dos produtos acabados é apresentada na Figura 5.

Para o teor de lactulose, não houve $(P>0,05)$ diferença entre os tempos de processamento (dia 0 e 30 dias), sendo o efeito do tratamento descrito na Tabela 1.
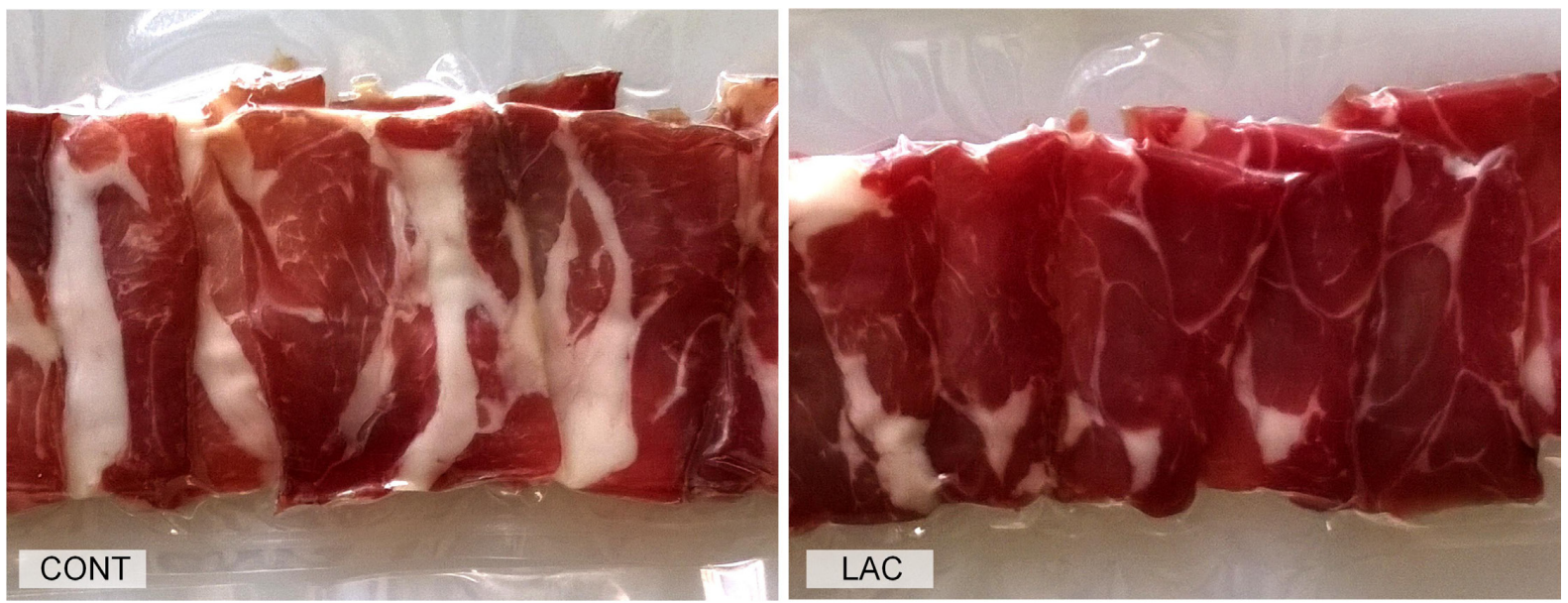

Figura 5. Fotos de fatias de presunto cru elaborado com (LACT) e sem (CONT) lactulose, embaladas à vácuo.

Tabela 1. Valores médios ( \pm desvio padrão) das características físicas e químicas de presuntos crus elaborados com (LACT) e sem (CONT) adição de lactulose.

\begin{tabular}{|c|c|c|c|c|}
\hline Característica & CONT & LACT & Média & $P>F^{*}$ \\
\hline Umidade (\%) & $44,61 \pm 4,25$ & $47,40 \pm 3,07$ & $46,00 \pm 3,65$ & 0,4089 \\
\hline Proteína (\%) & $33,31 \pm 2,05$ & $31,15 \pm 4,91$ & $32,23 \pm 3,57$ & 0,5219 \\
\hline Gordura (\%) & $16,35 \pm 0,94$ & $12,51 \pm 3,03$ & $14,43 \pm 2,90$ & 0,1038 \\
\hline Cinzas (\%) & $6,23 \pm 0,45$ & $6,41 \pm 0,20$ & $6,32 \pm 0,32$ & 0,5642 \\
\hline Lactulose (\%) & $0,17 \pm 0,03$ & $1,44 \pm 0,37$ & $0,68 \pm 0,69$ & 0,0001 \\
\hline Luminosidade $\left(L^{*}\right)$ & $48,20 \pm 5,58$ & $42,40 \pm 4,16$ & $45,30 \pm 9,41$ & 0,6691 \\
\hline Índice de vermelho $\left(a^{\star}\right)$ & $5,63 \pm 1,40$ & $4,24 \pm 0,62$ & $4,93 \pm 1,20$ & 0,1888 \\
\hline Índice de amarelo $\left(b^{\star}\right)$ & $5,11 \pm 0,57$ & $4,70 \pm 1,19$ & $4,91 \pm 0,80$ & 0,6743 \\
\hline Saturação $\left(C^{\star}\right)$ & $7,67 \pm 0,66$ & $6,34 \pm 1,29$ & $7,00 \pm 1,14$ & 0,2604 \\
\hline Ângulo de tonalidade $\left(h^{\star}\right)$ & $42,66 \pm 8,22$ & $47,69 \pm 3,13$ & $45,17 \pm 6,82$ & 0,4780 \\
\hline
\end{tabular}

${ }^{*}$ Diferenças significativas $(P<0,05)$ destacadas em negrito. 
O tratamento controle apresentou valores residuais desse dissacarídeo, provavelmente oriundo de interferências de aldoses presentes (ZHANG et al., 2010), como a glicose adicionada e os açúcares residuais presentes no xarope. Já o valor médio observado no produto acabado foi menor que a quantidade adicionada (2\%) e, considerando que durante o processo o produto perdeu cerca de $40 \%$ de sua massa, principalmente por evaporação de água, era esperado um aumento na concentração de solutos e, consequentemente, no teor de lactulose (para cerca de $2,4 \%)$. A inexistência de diferença $(P>0,05)$ entre o produto acabado e a massa cárnea indica uma possível utilização da lactulose como fonte de carbono para o crescimento de bactérias, provavelmente pelas bactérias ácido-láticas. Pennacchia et al. (2006) relataram que a lactulose foi um dos substratos mais eficazes para o crescimento de todas as oito estirpes de Lactobacillus por eles testadas. Saarela et al. (2003), estudando os efeitos de derivados de lactose nas propriedades funcionais e tecnológicas de estirpes de Lactobacillus potencialmente probióticas, concluíram que a lactulose foi o melhor substrato durante o crescimento anaeróbico, especialmente em concentrações entre $1 \%$ e $2 \%$.

A quantidade final de lactulose presente no tratamento LACT ficou bem abaixo do recomendado pela legislação brasileira (BRASIL, 2012) para ser considerado um produto "fonte de fibra alimentar" (2,5 g/porção) ou "alto conteúdo de fibra alimentar" (5,0 g/porção). Levando em consideração que os produtos possuíam cerca de 1,44\% de lactulose (analisados) e que a porção de presunto cru é de $40 \mathrm{~g}$ (BRASIL, 2003), a quantidade de lactulose presente em cada porção era de apenas $0,58 \mathrm{~g}$. No entanto, a aplicação de lactulose como prebiótico em alimentos é restrita a baixas doses. Schuster-Wolff-Bühring et al. (2010) relataram que doses diárias de $4 \mathrm{~g}$ até $10 \mathrm{~g}$ de lactulose são suficientes para exercerem ação prebiótica em adultos. Terada et al. (1992) observaram que uma alimentação diária de $3 \mathrm{~g}$ de lactulose durante duas semanas aumentou significativamente o número de Bifidobacteria na flora fecal, enquanto os números de clostridia, streptococcie Enterobacteriaceae foram reduzidos.

Apesar de um consumo diário de 6 a 7 porções de presunto cru elaborado com $2 \%$ de lactulose poder proporcionar efeitos positivos para a saúde e prevenção de doenças, deve-se considerar que essa é uma quantidade relativamente alta para o consumo desse tipo de produto. No entanto, uma vez que nenhum fator de qualidade avaliado neste experimento foi afetado, positiva ou negativamente, pela adição da lactulose, pode ser possível utilizar maiores quantidades desse dissacarídeo na elaboração de presuntos crus desossados, aumentando-se assim a quantidade de lactulose na porção.

\section{Conclusão}

Não houve alterações físicas, químicas ou microbiológicas no presunto cru oriundas da adição da lactulose, não se alterando, portanto, os parâmetros de qualidade dos produtos. Dessa forma, concluiu-se que é potencialmente viável a utilização da lactulose como prebiótico na elaboração de presuntos crus desossados com vistas à alegação de produto com propriedade funcional. Ressalta-se, no entanto, a necessidade de se avaliar os efeitos dessa adição na qualidade sensorial dos produtos elaborados.

\section{Agradecimentos}

Os autores agradecem ao Conselho Nacional de Desenvolvimento Científico e Tecnológico (CNPq; 476355/2012-5) pelo apoio financeiro à execução do projeto e à Universidade Federal de Lavras pela bolsa de iniciação científica do segundo autor (PIBIC/UFLA).

\section{Referências}

BERGAMIN FILHO, W.; COSTA, M. D. R.; FELÍCIO, P. E. D.; SILVEIRA, E. T. F. Método acelerado de processamento de presunto cru. Food Science and Technology, Campinas, v. 30, n. 2, p. 494-500, 2010. http://dx.doi.org/10.1590/S010120612010000200030.

BERMÚDEZ, R.; FRANCO, D.; CARBALLO, J.; LORENZO, J. M. Physicochemical changes during manufacture and final sensory characteristics of dry-cured Celta ham: effect of muscle type. Food Control, Guildford, v. 43, p. 263-269, 2014. http://dx.doi. org/10.1016/j.foodcont.2014.03.028.

BRASIL. Ministério da Saúde. Agência Nacional de Vigilância Sanitária. Portaria n 398, de 30 de abril de 1999. Aprova o regulamento técnico que estabelece as diretrizes básicas para análise e comprovação de propriedades funcionais e ou de saúde alegadas em rotulagem de alimentos. Diário Oficial [da] República Federativa do Brasil, Brasília, DF, 1999. Seção 1.

BRASIL. Ministério da Agricultura, Pecuária e do Abastecimento. Secretaria de Defesa Agropecuária. Instrução Normativa $n^{\circ} 22$, de 31 de julho de 2000. Aprova os regulamentos técnicos de identidade e qualidade de copa, de jerked beef, de presunto tipo Parma, de presunto cru, de salame, de salaminho, de salame tipo alemão, de salame tipo calabrês, de salame tipo friolano, de salame tipo napolitano, de salame tipo hamburguês, de salame tipo italiano, de salame tipo milano, de lingüiça colonial e pepperoni. Diário Oficial [da] República Federativa do Brasil, Brasília, DF, 2000. Seção 1, p. 17-18.

BRASIL. Ministério da Saúde. Agencia Nacional de Vigilância Sanitária. Secretaria de Vigilância Sanitária. Resolução RDC n 12, de 02 de janeiro de 2001. Aprova o Regulamento Técnico sobre padrões microbiológicos para alimentos. Diário Oficial 
Caracterização física, química e microbiológica de presunto cru desossado adicionado de lactulose

Lima, I. A. et al.

[da] República Federativa do Brasil, Brasília, DF, 2001. Seção 1, p. 11-E.

BRASIL. Ministério da Saúde. Agência Nacional de Vigilância Sanitária. Resolução RDC n 360, de 23 de dezembro de 2003. Aprova o Regulamento Técnico sobre rotulagem nutricional de alimentos embalados. Diário Oficial [da] República Federativa do Brasil, Brasília, DF, 2003. Seção 1.

BRASIL. Ministério da Agricultura, Pecuária e Abastecimento. Secretaria de Defesa Agropecuária. Instrução Normativa n ${ }^{\circ} 51$, de 29 dezembro de 2006. Aprova o Regulamento Técnico de atribuição de aditivos, e seus limites das seguintes categorias de alimentos 8: carne e produtos cárneos. Diário Oficial [da] República Federativa do Brasil, Brasília, DF, 2006.

BRASIL. Alegações de propriedade funcional aprovadas. Brasília: ANVISA, 2008.

BRASIL. Ministério da Saúde. Agência Nacional de Vigilância Sanitária. Resolução RDC n 54, de 12 de novembro de 2012. Dispõe sobre o Regulamento Técnico sobre informação nutricional complementar. Diário Oficial [da] República Federativa do Brasil, Brasília, DF, 2012. Seção 1.

COSTA, M. R.; BERGAMIN FILHO, W.; CIPOLLI, K. M. V. A. B.; SILVEIRA, E. T. F.; FELÍCIO, P. E. Perfil sensorial e aceitação de presuntos crus produzidos por métodos tradicionais e acelerado. Food Science and Technology, Campinas, v. 27, n. 1, p. 170-176, 2007. http://dx.doi.org/10.1590/S0101-20612007000100030.

COSTA, M. R.; BERGAMIN FILHO, W.; SILVEIRA, E. T. F.; FELÍCIO, P. E. Colour and texture profiles of boneless reestructured dry-cured hams compared to traditional hams. Scientia Agricola, Piracicaba, v. 65, p. 169-173, 2008.

COUTRON-GAMBOTTI, C.; GANDEMER, G. Lipolysis and oxidation in subcutaneous adipose tissue during dry-cured ham processing. Food Chemistry, London, v. 64, n. 1, p. 95-101, 1999. http://dx.doi.org/10.1016/S0308-8146(98)00079-X.

FERNÁNDEZ-SALGUERO, J. Conservación de productos cárneos por aplicación de factores combinados: produtos españoles de humedade intermedia y alta. Revista Española de Ciencia y Tecnologia de Alimentos, Valencia, v. 35, n. 3, p. 233-246, 1995.

FOOD AND AGRICULTURE ORGANIZATION OF THE UNITED NATIONS - FAO. FAO technical meeting on prebiotics. Rome: FAO, 2008. p. 1-12.

FREY, W. Fabricación fiable de embutidos. Zaragoza: Acribia, 1983. 194 p.

HONIKEL, K. O. The use and control of nitrate and nitrite for the processing of meat products. Meat Science, Oxford, v. 78, n. 1-2, p. 68-76, 2008. PMid:22062097. http://dx.doi.org/10.1016/j. meatsci.2007.05.030.

HORWITZ, W. (Ed.). Official methods of analysis of the Association of Official Analytical Chemists. 17th ed. Gaithersburg, MD: AOAC, 2002.
MATOS, R. A.; MENEZES, C. M.; RAMOS, E. M.; RAMOS, A. L. S.; GOMIDE, L. A. M. Efeito do tipo de fermentação na qualidade final de embutidos fermentados cozidos elaborados a base de carne ovina. Boletim Ceppa, Curitiba, v. 25, p. 225-234, 2007.

PALHARES, P. C.; DUTRA, M. P.; RAMOS, E. M.; RAMOS, A. L. S.; PEREZ, J. R. O.; GOMIDE, L. A. M. Caracterização físico-química de perna de cordeiro desossada, curada e dessecada elaborada com glucona delta lactona. In: CONGRESSO BRASILEIRO DE CIÊNCIA E TECNOLOGIA DE CARNES, 6., 2011, Águas de São Pedro. Anais... Águas de São Pedro: ITAL/CTC, 2011. 4 p.

PANESAR, P. S.; KUMARI, S. Lactulose: production, purification and potential applications. Biotechnology Advances, Oxford, v. 29 , n. 6, p. 940-948, 2011. PMid:21856402. http://dx.doi. org/10.1016/j.biotechadv.2011.08.008.

PEGG, R. B.; SHAHIDI, F. S. Nitrite curing of meat: the $\mathrm{N}$-nitrosamine problem and nitrite alternatives. Trumbull: WileyBlackwell, 2000. 268 p.

PENNACCHIA, C.; VAUGHAN, E. E.; VILLANI, F. Potential probiotic Lactobacillus strains from fermented sausages: Further investigations on their probiotic properties. Meat Science, Oxford, v. 73, n. 1, p. 90-101, 2006. PMid:22062058. http:// dx.doi.org/10.1016/j.meatsci.2005.10.019.

PUOLANNE, E.; PETÄJÄ-KANNINEN, E. Principles of meat fermentation. In: TOLDRÁ, F.; HUI, Y. H.; ASTIASARAN, I.; SEBRANEK, J.; TALON, R. (Eds.). Handbook of fermented meat and poultry. New York: John Wiley \& Sons, 2014. p. 13-17.

RAHARJO, S.; SOFOS, J. N.; SCHMIDT, G. R. Improved speed, specificity, and limit of determination of an aqueous acid extraction thiobarbituric acid-C18 method for measuring lipid peroxidation in beef. Journal of Agricultural and Food Chemistry, Washington, v. 40, n. 11, p. 2182-2185, 1992. http:// dx.doi.org/10.1021/jf00023a027.

RAMOS, E. M.; GOMIDE, L. A. M. Avaliação da qualidade de carnes: fundamentos e metodologias. Viçosa: Editora UFV, 2007. 599 p.

ROMERO DE ÁVILA, M. D.; HOZ, L.; ORDÓÑEZ, J. A.; CAMBERO, M. I. Dry-cured ham restructured with fibrin. Food Chemistry, London, v. 159, p. 519-528, 2014. PMid:24767091. http://dx.doi. org/10.1016/j.foodchem.2014.03.051.

RUIZ, J.; GARCÍA, C.; MURIEL, E.; ANDRÉS, A. I.; VENTANAS, $J$. Influence of sensory characteristics on the acceptability of dry-cured ham. Meat Science, Oxford, v. 61, n. 4, p. 347-354, 2002. http://dx.doi.org/10.1016/S0309-1740(01)00204-2.

SAARELA, M.; HALLAMAA, K.; MATTILA-SANDHOLM, T.; MÄTTÖ, J. The effect of lactose derivatives lactulose, lactitol and lactobionic acid on the functional and technological properties of potentially probiotic Lactobacillus strains. International Dairy Journal, Barking, v. 13, n. 4, p. 291-302, 2003. http://dx.doi. org/10.1016/S0958-6946(02)00158-9. 
Caracterização física, química e microbiológica de presunto cru desossado adicionado de lactulose Lima, I. A. et al.

SCHOLZ-AHRENS, K. E.; SCHAAFSMA, G.; VAN DEN HEUVEL, E. G.; SCHREZENMEIR, J. Effects of prebiotics on mineral metabolism. American Journal of Clinical Nutrition, Bethesda, v. 73, n. 2, p. 459s-464s, 2001. Supplement. PMid:11157358. SCHUSTER-WOLFF-BÜHRING, R.; FISCHER, L.; HINRICHS, J. Production and physiological action of the disaccharide lactulose. International Dairy Journal, Barking, v. 20, n. 11, p. 731-741, 2010. http://dx.doi.org/10.1016/j.idairyj.2010.05.004.

SILVA, N.; JUNQUEIRA, V. C. A.; SILVEIRA, N. F. A. Manual de métodos de análise microbiológica de alimentos. 2. ed. São Paulo: Livraria Varela, 2001.

TAMURA, Y.; MIZOTA, T.; SHIMAMURA, S.; TOMITA, M. Lactulose and its application to the food and pharmaceutical industries. Bulletin of the International Dairy Federation, Brussels, v. 289, p. 43-53, 1993.
TERADA, A.; HARA, H.; KATAOKA, M.; MITSUOKA, T. Effect of lactulose on the composition and metabolic activity of the human faecal flora. Microbial Ecology in Health and Disease, Oslo, v. 5, n. 1, p. 43-50, 1992. http://dx.doi.org/10.3109/08910609209141303. TERRA, N. N.; TERRA, A. B. M.; TERRA, L. M. Defeitos nos produtos cárneos: origens e soluções. São Paulo: Livraria Varela, 2004

TOLDRA, F. Dry-cured meat products. Connecticut: Food \& Nutrition Press, 2002. 224 p.

ZHANG, Z.; WANG, H.; YANG, R.; JIANG, X. A novel spectrophotometric method for quantitative determination of lactulose in food industries. International Journal of Food Science \& Technology, Oxford, v. 45, n. 2, p. 258-264, 2010. http://dx.doi.org/10.1111/j.1365-2621.2009.02129.x. 